Running Head: Inoculating truth-tellers' memory as a function of encoding quality

\title{
Amplifying recall after delays via initial interviewing: \\ Inoculating truth-tellers' memory as a function of encoding quality
}

\author{
Adam Charles Harvey* \\ Department of Psychology, University of Portsmouth \\ Aldert Vrij \\ Department of Psychology, University of Portsmouth \\ Sharon Leal \\ Department of Psychology, University of Portsmouth \\ Haneen Deeb \\ Department of Psychology, University of Portsmouth \\ Lorraine Hope \\ Department of Psychology, University of Portsmouth \\ Samantha Mann \\ Department of Psychology, University of Portsmouth
}

\begin{abstract}
*Correspondence concerning this article should be addressed to Adam C. Harvey, University of Portsmouth, Department of Psychology, King Henry Building, King Henry Street, Portsmouth PO1 2DY, Portsmouth, United Kingdom. Email: adam.harvey@port.ac.uk
\end{abstract}

This work is funded by the High-Value Detainee Interrogation Group, DJF-15-1200- V0010196 awarded to the University of Portsmouth (UK). Any opinions, findings, conclusions, or recommendations expressed in this article are those of the authors and do not necessarily reflect the views of the U.S. Government. 
Running Head: Inoculating truth-tellers' memory as a function of encoding quality

\section{Abstract (196 words)}

Typically, truth-tellers report more detailed statements when interviewed immediately, compared to after delays (displaying forgetting), whereas liars report statements containing similar amounts of detail when interviewed immediately or after a delay (displaying a metacognitive error). Accordingly, the diagnostic utility of the 'richness-of-detail' cue is reduced after delays. We investigated if initial interviewing can facilitate lie-detection using the richness-of-detail cue in sub-optimal memorial conditions, that is, when (i) interviewing occurred after a three-week delay and (ii) truth-teller's attention during encoding was manipulated. Participants $(n=152)$ witnessed an interaction, that was meaningful to (and intentionally encoded by) liars $(n=50)$ and half of truth-tellers $(n=51)$, but meaningless (and incidentally encoded by) the remaining truth-tellers $(n=51)$. Participants were interviewed after three weeks. Half of the intentional liars and half of the intentional and incidental truthtellers were also interviewed immediately (initial interview-present condition), whereas the remaining participants received no immediate interview (initial interview-absent condition). Results showed intentional and incidental truth-tellers reported after three weeks more detail in the initial interview-present (versus absent) condition, whereas intentional liars' statements were unaffected by initial interviewing condition. After three weeks, more intentional liars and intentional truth-tellers were correctly distinguished in the initial interview-present (versus absent) condition. 
Running Head: Inoculating truth-tellers' memory as a function of encoding quality

\section{General Audience Summary (136 words)}

When interviewing occurs immediately following an event, truth-tellers typically report more detailed statements than liars, and 'richness-of-detail' is a reliable cue to deception. However, after delays, truth-tellers show evidence of forgetting (i.e. providing less detailed statements), whereas liars do not. We investigate if initial interviewing can facilitate lie-detection using the richness-of-detail cue in sub-optimal recall conditions, that is when (i) interviewing occurred after a three week delay and (ii) truth-teller's attention during encoding was manipulated. Results showed truth-tellers who encoded events intentionally (with deliberate attention) and incidentally (without attention) reported more detailed statements after three weeks in the initial interview-present (versus absent) condition, whereas liars' statements were unaffected by initial interviewing condition. After three weeks, more liars and intentional encoding truth-tellers were correctly distinguished using richness-of-detail as a cue in the initial interview-present (versus absent) condition.

Key Words (5): Deception; initial interviewing; memory; forgetting; encoding

Word counts: Introduction: (1432); Discussion: (1389); Total excluding tables; references; appendix; and supplementary analysis: (7355) 
Running Head: Inoculating truth-tellers' memory as a function of encoding quality

\section{Amplifying recall after delays via initial interviewing: \\ Inoculating truth-tellers' memory as a function of encoding quality}

'...[T]he memory of everything is very soon overwhelmed in time'

- Marcus Aurelius, Meditations.

In traditional lie-detection experimenters, truth-tellers and liars are interviewed immediately after a to-be-remembered (TRB) event that is meaningful (or made meaningful) to all interviewees (Harvey, Vrij, Leal, Hope \& Mann, 2017b; Izotovas et al., 2018; Vrij, 2008; 2016). In these near-optimal recall conditions, truth-tellers typically report more detailed statements than liars (DePaulo et al., 2003; Vrij, 2005, 2015), and richness-of-detail (Nahair \& Pazuelo, 2015; Nahari \& Vrij, 2015) is a diagnostic cue to deception (Amado, Arce, Fariña, \& Vilarino, 2016; Masip, Sporer, Garrido \& Herrero, 2005; Oberlader et al., 2016). However, forensic interviews often occur after extended delays (Gabbert, Hope \& Fisher, 2009; Kebbell \& Wagstaff, 1996; 1999) and sometimes concern events that were incidental or not directly relevant to witnesses (Harvey et al., 2017b). In these 'suboptimal' conditions, truth-tellers are less able to report richly detailed statements due to relying on weaker incidental memory traces and forgetting information (Harvey, Vrij, Hope, Leal \& Mann, 2017a; Izotovas et al., 2018; Nahari, 2018). In contrast, liar's statements appear insensitive to the deleterious effects of delay, plausibly because they can fabricate detail and do not exclusively rely upon fragile episodic memory to report statements (Harvey et al., 2017a). Thus, suboptimal conditions reduce the diagnosticity of the richness-of-detail cue (Harvey, Vrij, Hope, Leal \& Mann, 2019; Harvey et al., 2017a; 2017b). 
Running Head: Inoculating truth-tellers' memory as a function of encoding quality

This study examines a means of amplifying lie-detection performance using the richness-of-detail cue in suboptimal recall conditions; specifically, when (i) interviewing occurs after a three-week delay and (ii) truth-teller's encoding quality is manipulated. Our aims are threefold. First, we explore if initial interviewing reinforces truth-tellers' memory for a TBR-event, facilitating the reporting of more detailed statements after a three-weeks delay (versus an initial interview-absent condition). Second, we investigate if the inoculating effects of initial interviewing vary as a function of truth-teller's intentional (with deliberate attention) or incidental (without deliberate attention) encoding quality (Harvey et al., 2017b; Kontaxopoulou et al., 2017; Unsworth \& Spillers, 2010). Third, we test the hypothesis that initial interview will enhance the utility of the 'richness-of-detail' cue for correctly distinguishing between (i) liars; (ii) intentional; and (iii) incidentally encoding truth-tellers, during delayed interviewing.

Genuine statements are derived from memory (Johnson \& Raye, 1981; Nahari \& BenShakhar, 2011; Vrij, 2016) and memory performance is time-critical (Anderson, 1983; Ayers \& Reder, 1998; Wixted \& Carpenter, 2007). In immediate interviewing paradigms, truthtellers typically report more detailed statements than liars (DePaulo et al., 2003; Vrij, 2005, 2008, 2015) and richness-of-detail is a diagnostic cue (Amado et al., 2016; Masip, et al., 2005; Oberlader et al., 2016). However, as the delay between witnessing an incident and reporting increases, the accessibility of information decreases (Penrod, Loftus \& Winkler, 1982; Wixted \& Ebbesen, 1997). Information is initially lost from memory rapidly before plateauing, in a pattern known as the forgetting curve (Ebbinghaus, 1885; Murre \& Dros, 2015). In terms of the quality of details recalled, specific information rapidly decays and statements become more gist-like over time (Fisher, 1996; Goldsmith, Koriat \& Pansky, 2005; Koriat, Levy-Sadot \& de Marcas, 2003; Reyna \& Kiernan, 1994). Accordingly, 
Running Head: Inoculating truth-tellers' memory as a function of encoding quality

forgetting can constrain truth-tellers' statements, reducing the quantity of details reported after delays (Harvey et al., 2017a; Nahari, 2018; Izotovas et al., 2018).

Liars' statements appear less time-critical (Harvey et al., 2017a), presumably because they are not exclusively derived from episodic memory (Johnson \& Raye, 1981; Vrij, 2008) and can be manufactured using fabricated detail (Nahari, 2018). After delays, liars fail to correctly simulate truth-teller's forgetting curve, reporting similarly detailed statements in delayed and immediate interviewing conditions (Harvey et al., 2017a; 2017b; 2019; Nahari, 2018; Izotovas et al., 2018). Whereas truth-tellers report less detail over time, liars do not. Liar's insensitivity to the effects of delay, and failure to correctly estimate memory performance, represents a metacognitive error referred to as a stability bias (Harvey et al., 2017a; see Koriat, Bjork, Sheffer, Bar, 2004; Kornell et al., 2009).

In sum, after delays the utility of the richness-of-detail cue is impaired as a byproduct of two effects: (i) forgetting amongst truth-tellers, and (ii) the stability bias amongst liars. As forgetting constrains truth-teller's reporting of detailed information, one means of enhancing lie-detection using richness-of-detail as a cue is via enhancing genuine recall after delays (Harvey et al., 2019).

Initial interviewing can inoculate memory from the deleterious effects of forgetting (Ebbesen \& Rienick, 1998; Gabbert, Hope, Fisher \& Jamieson, 2012; Hope, Gabbert, Fisher \& Jamieson, 2014), in a process analogous to the 'Testing Effect' (Dempster, 1996; Roediger \& Karpicke, 2006a, 2006b). Associative Network models of memory (e.g. Anderson, 1976, 1983a, 1983b; Smith, 1998) attribute this inoculation effect to the elaboration and activation of memory trace that occur during successful retrieval (Roediger \& Butler, 2011). Initial recall can increase the activation levels of items of information, and increase the associations between items, enhancing the extent such items are integrated together in an episodic memory trace (Anderson, 1983; Ayers \& Reder, 1998; Damasio, 1989). Retrieval can also 
Running Head: Inoculating truth-tellers' memory as a function of encoding quality

enhance subsequent recall by creating alternative revival pathways to encoded information in memory (Bjork, 1988).

As truth-tellers can only accurately report information retrieved from memory (Harvey et al., 2017a), initial interviewing (versus an initial interview-absent condition) should inoculate memory and amplify delayed recall performance, facilitating the reporting of more detailed statements. Conversely, liars may not benefit from the inoculating effects of initial interviewing, as they report fabricated information rather than relying exclusively upon genuine memory (Harvey et al., 2019; Nahari, 2018). Initial interviewing instructions do not inform interviewees regarding any potential enhancement of subsequent memory performance induced by the intervention and liars may not be aware of this effect.

To accurately feign the inoculating effects of initial interviewing requires liars to have astute metacognition (cognition regarding mental processes). However, individuals frequently display erroneous metacognition, especially regarding memory performance (Koriat et al., 2004; Kornell et al., 2009). Therefore, liars may fail to correctly estimate the appropriate quantity of detail to disclose in response to initial interviewing after a delay. Thus, an initial interview may have a mnemonic effect upon truth-tellers' recall performance that liars (i) do not benefit from; (ii) are unaware of; and/or (iii) are unable to simulate.

Storage and retrieval of episodic memory (explicit memory about experienced events; Tulving, 1972; 1993) is predicated upon the encoding of perceptual information (Craik \& Tulving, 1975). Episodic memory traces can be either intentionally or incidentally encoded (Kontaxopoulou et al., 2017; Unsworth \& Spillers, 2010). These operations differ in the extent selective attention (see Mulligan, 1998) is applied during encoding: intentional encoding refers to when attention is deliberately applied, whereas incidental encoding refers to when no deliberate attention is applied (Kontaxopoulou et al., 2017). When attention is divided during encoding, subsequent memory performance is reduced (e.g. Craik, Govoni, 
Running Head: Inoculating truth-tellers' memory as a function of encoding quality

Naveh-Benjamin, \& Anderson, 1996; Krix, Sauerland, Gabbert \& Hope, 2014; Mulligan, 2003; Sauer \& Hope, 2016). Although intentional and incidental encoding operations are relevant to deception research (Harvey et al., 2017b), incidental encoding is considered most prominent in real-life settings (Kontaxopoulou et al., 2017).

It is theoretically unclear if the inoculation effects of initial interviewing vary as a function of truth-teller's encoding operations. In relative terms, incidental traces are less enduring and decay more rapidly than intentional traces (Kontaxopoulou et al., 2017; Unsworth \& Spillers, 2010). Therefore, truth-tellers reliant upon incidental traces may be unable to report detailed statements during initial interviewing due to extensive forgetting. If initial interviewing preserves subsequent memory performance by increasing the accessibility of previously recalled information (e.g. Hope et al., 2014), then an impaired ability to recall information during initial interviewing may reduce the resultant inoculation effect. However, in absolute terms, any information retrieved and reported during initial interviewing should be preserved and subsequently more accessible (compared to when no initial interviewing is provided), irrespective of truth-teller's original encoding quality. Therefore, initial interviewing may inoculate both intentional and incidental traces, but to differing extents.

Based upon the above theoretical considerations, we predict that initial interviewing will have an inoculating effect on truth-tellers verbal statements after delays, but not liars. Specifically, we hypothesise that during delayed interviewing, intentionally and incidentally encoding truth-tellers in the initial interview-present condition will report more detailed statements, compared to intentionally and incidentally encoding truth-tellers in the initial interview-absent condition. We hypothesise that during delayed interviewing, the quantity of detail reported by intentional liars will not vary as a function of initial interviewing (Hypothesis 1). 
Running Head: Inoculating truth-tellers' memory as a function of encoding quality

Furthermore, as a consequence of the above predicted results, we hypothesise that during delayed interviewing, more intentional liars, intentionally encoding truth-tellers, and incidentally encoding truth-tellers will be correctly distinguished using detail as a cue in the initial interview-present (versus the initial interview-absent) condition (Hypothesis 2). 
Running Head: Inoculating truth-tellers' memory as a function of encoding quality

\section{Design}

\section{Method}

A 3 (Veracity: Intentional encoding truth-teller vs. Incidental encoding truth teller vs. Intentional liar $) \times 2$ (Initial interviewing: Initial interview-present vs. Initial interview-absent) between subjects experimental design was used. The dependent variable was the total number of spatial, temporal and perceptual details reported during the delayed interview, which were summated to calculate a 'total detail reported' variable.

\section{Participants $^{\mathrm{I}}$}

An a priori power analysis using G*Power (Faul, Erdfelder, Lang \& Buchner, 2007; Faul, Erdfelder, Buchner \& Lang, 2009), assuming a medium effect size of $f=0.25$ ( $\alpha=$ 0.05 ) for six groups, indicated a sample size of 158 would be sufficient for power of 0.80 (Cohen, 1988, 1992). A total of 158 participants were recruited. Of those 152 volunteers, comprising of 106 females and 46 males, aged between 18 and 51 years $(M=23.23$ years, $S D$ $=5.88,95 \% \mathrm{CI}[22.23,24.14])$, from the University's undergraduate $(n=114)$, postgraduate $(n=26)$ and staff $(n=12)$ communities participated in the study in exchange for a small honorarium ( $£ 10$ in the initial interview-absent condition, $£ 15$ for the initial interviewpresent condition) and a chance to win in a raffle one of three additional cash prizes ( $£ 50$, $£ 100$ or $£ 150$ ). The remaining six participants did not complete the study.

\section{Procedure}

The procedure was adapted from previous research (Harvey et al., 2017a; 2017b; 2019). Participants watched a video recording and also witnessed a social interaction. The latter is the target event. The video recording element was included in the design to distract the truthtellers in the incidental encoding condition (incidental truth-tellers) from the target event of the experiment (the social interaction). The attention of both truth-tellers and liars in the intentional encoding condition was directed towards the social interaction by making it critical to their mission goal, and therefore meaningful. In contrast, no indication was given 
Running Head: Inoculating truth-tellers' memory as a function of encoding quality

to incidental truth-tellers that the social interaction was part of the study.

Participants were recruited via adverts on the University's online participant recruitment platform and posters placed around the University. The adverts solicited individuals to participate in a study on deception in intelligence settings. Individuals who had previously taken part in similar previous research were not eligible to participate.

All participants arrived individually at the laboratory at pre-arranged times. Each participant was given an information sheet about the study and informed written consent was obtained. Participants were randomly allocated to the intentional encoding truth teller $(n=$ $51)$, incidental encoding truth teller $(n=51)$, or intentional encoding liar $(n=50)$ veracity conditions. Half of the participants per group where then randomly allocated to either the initial interview-absent (control) condition $(n=77)$ with no initial interview, or the initial interview-present condition $(n=75)$. All participants were told the experiment involved assuming the role of an intelligence operative with access to a "classified video recording" of an intelligence briefing. We have used this recording (video) in previous research (Ewens, Vrij, Jang \& Jo, 2014; Ewens, Vrij, Mann \& Leal, 2015; Harvey et al., 2017a Experiment 1; 2017b; 2019; Shaw et al., 2013). The video ostensibly shows intelligence operatives who are planning to plant a surveillance device. All participants were told they should try and remember as many details about the briefing video as possible. Additionally, it was explained (a) that note taking was prohibited and (b) that the briefing video could only be observed once. All participants were told they would be interviewed later about the briefing video.

\section{Incidental truth-teller instructions}

Truth-tellers in the incidental encoding condition $(n=51)$ were told that for the experiment they are in the Blue team and will be interviewed by a member of their own team. As such, they should be totally truthful to the interviewer and provide them with as much information as they can recall. 
Running Head: Inoculating truth-tellers' memory as a function of encoding quality

\section{Intentional truth-teller instructions}

Truth-tellers in the intentional encoding condition $(n=51)$ were given the same information as incidental truth-tellers. Additionally, intentional truth-tellers were informed that there are also participants on the Red team taking part in the experiment at the same time, and thus they should be mindful as to what members of other teams may be doing. They were instructed that if they encountered anyone using the code words "rocket science," this meant that those people were also on their Blue team. They were also informed that if they did not hear those words then they could assume that the other participants were members of the opposing Red team and the truth-tellers should pay attention to anything they do. It was explained that such information might be useful to the Blue team later in the experiment.

\section{Intentional liar instructions}

All liars were intentional liars $(n=50)$. They were told that for the experiment they were on the Red team and would be interviewed by a member of the opposing Blue team and as such their task was to mislead the interviewer about certain details of the video, including (a) what the surveillance device looked like, (b) it's functions, and also (c) the location that was chosen to plant the device. They were informed that the interviewer knew that the device would be placed somewhere but did not know where. They were instructed that they should not reveal the location that was selected to hide the surveillance device and that their objective was to mislead the investigator by reporting that the third location mentioned in the video was, in fact, the location in which the device would be planted. They were also told to lie about the device itself. Liars were informed the interviewer knew something about the device but did not have all the details, and that it was not clear exactly what the interviewer knew. Because of this, liars were told to provide some truthful and some false information about the surveillance device, as this would help them appear cooperative without revealing everything to the interviewer. Finally, they were informed they should be mindful as to what 
Running Head: Inoculating truth-tellers' memory as a function of encoding quality

other Red team members may be doing in the experiment. Liars were told that if they encountered anyone during the study who used the code word "thermodynamics", those individuals were also on the Red team. Critically, the interviewer of the opposing Blue team would probably be aware that they were taking part so they should not deny seeing them. However, participants were also instructed that they should protect these individuals' identities by not telling the truth about what Red team members looked like and what they said, if asked by the interviewer.

\section{General pre-interview instructions}

All participants were told that if the interviewer judged them as credible, they would receive $£ 10$ (in the initial interview-absent condition) or $£ 15$ (in the initial interview-present condition). This difference in compensation was pragmatic, due to the requirement in the initial interview-present condition to attend longer experimental sessions (approximately 6090 minutes over two sessions) compared with participants in the initial interview-absent (control) condition (approximately 45 minutes over two sessions).

Participants were also informed that interviewees judged by the interviewer as truthful would be entered into a prize draw to win up to $£ 150$ in prize money. However, participants not judged as truthful would instead be asked to write a time-consuming statement about what happened during the study. Participants were instructed not to discuss the study with others and then taken to the waiting room and told to wait until the experimenter collected them to view the video.

\section{Target Event}

While waiting to watch the intelligence video, all participants witnessed the staged social interaction event (the focus of the current study). This event consisted of a conversation, followed by a document exchange, between two confederates (unknown to the participants). 
Running Head: Inoculating truth-tellers' memory as a function of encoding quality

Upon entering the waiting room, the participant was instructed to take a seat (the seat location was identical for all participants) and wait to be collected by the experimenter. One confederate (A) was already seated in the waiting room (again, this confederate location was identical for all participants). After 30 seconds, a second confederate (B) entered the waiting room and walked past the participant to sit next to the first confederate. Both confederates then engaged in the scripted exchange (which included the word 'thermodynamics'), before a third confederate entered the waiting room with an inquiry before leaving. The exchange then continued between confederates $\mathrm{A}$ and $\mathrm{B}$ before the experimenter returns and collects the participant (for a full description of the exchange, see Appendix 1).

To check the standardisation of the scripted protocol, the duration of the staged social interaction was recorded for each participant $(M=101.42$ seconds; range: $80-135 ; S D=$ $11.09,95 \%$ CI $[99.64,103.19])$. To confirm there was no unintended systematic variation in the duration of the staged event by condition, a 3 (Veracity: intentional truth vs. incidental truth vs. lie) x 2 (Initial interviewing: Absent vs. present) ANOVA was conducted. No significant main effects emerged for Veracity, $F(2,146)=1.502, p=.226, f=0.14, \mathrm{BF}_{01}=$ 4.194, or Initial interviewing, $F(1,146)=1.072, p=.302, f=0.08, \mathrm{BF}_{01}=3.483$. Furthermore, no significant Veracity $\times$ Initial interviewing interaction effect emerged, $F(2,146)=.948, p=.390, f=0.11, \mathrm{BF}_{01}=14.982$.

Immediately after completion of the social interaction target event, the experimenter entered the room to collect the participant and escort him/her to watch the intelligence video in the laboratory. Once seated, the participants were presented the intelligence video, which lasted 6 minutes and 29 seconds, on a laptop. After the video, participants in the initial interview-absent (control) condition where told that they had completed the first phase of the study. On their return after three weeks, participants in the control condition progressed to the interviewing phase of the study. Participants in the initial interview-present condition 
Running Head: Inoculating truth-tellers' memory as a function of encoding quality

progressed into the initial interviewing phase of the study.

\section{Initial interviewing phase}

The experimenter began the interviewing phase of the experiment by informing participants that they would be questioned about both the intelligence video and the social interaction in the waiting room. Experimental instructions were repeated and summarised for all participants. Participants were offered as much time as they required prior to the interview to prepare themselves.

After indicating they were ready for the interview, all participants completed the preinterview questionnaire. The participants were asked for their demographic information (age, gender, occupation) and to rate their preparation for the interview (on 7-point Likert scales, ranging from 1 (very poor) to 7 (very good); 1 (pointless) to 7 (useful); 1 (insufficient) to 7 (sufficient); and 1 (incomplete) to 7 (thorough). These four items were clustered into one ‘preparation' variable, Cronbach's alpha $=.87$.

All interviews were conducted identically. Our interview protocol consisted of five questions concerned the social interaction (the focus of the current study) and three questions concerning the video (see Appendix 2 for questioning protocol). After the interview, arrangements for the return phase (three-weeks later) were finalized with participants in the initial interview-present condition.

\section{Delayed interviewing phase}

With the exception of six individuals who did not return to complete the study, participants $(n=152)$ returned to be interviewed three weeks after the first phase of the study $(+/-1$ day; $M=21.11$ days, $S D=.82,95 \%$ CI $[20.98,21.24])$. Interviewees where told this second phase was to examine the effects of delay on cues to deception. This delayed interview was conducted identically to that of the immediate interview, with one exception: after the interview was finished, all participants completed a post-interview questionnaire. 
Running Head: Inoculating truth-tellers' memory as a function of encoding quality

Two interviewers (male and female postgraduate research students) were used interchangeably throughout the experiment. All interviews were audio and video recorded. Both interviewers were blind to the experimental condition of the interviewees and had not viewed the intelligence recording. There was no statistically significant difference between interviewer one $(M=124.42, S D=61.27,95 \% \mathrm{CI}[109.83,139.72])$ and interviewer two $(M$ $=119.02, S D=62.47,95 \% \mathrm{CI}[106.65,133.00])$ with respect to 'total detail' reported for the social interaction, $t(150)=.520, p=.604, d=.07 .95 \% \mathrm{CI}[-.29, .43], \mathrm{BF}_{01}=4.912$.

The post-interview questionnaire asked participants to report their motivation for performing well during the interview (on a 7-point Likert Scale, ranging from 1 extremely unmotivated to 7 extremely motivated), to estimate the likelihood (on an 11-point Likert scale, ranging from $0 \%$ to $100 \%$ likely) of receiving the monetary reward and having to write the statement, and to report percentage of truthful information they disclosed in the interview (also on an 11-point Likert Scale, ranging from $0 \%$ to $100 \%$ ). Upon completion participants where thanked, debriefed and compensated for their time.

\section{Coding}

All audiotapes were transcribed, and the verbal coding was conducted using these transcripts. The statements were rated by one coder (blind to the experimental conditions) who scored the occurrence of perceptual detail (information about what was seen, heard, felt, and smelt during the described activities; e.g., "She talked loudly," "There was man in a jacket already there"), spatial detail (information about locations or the arrangement of persons and/or objects; e.g., "the sofa in the far left corner of the room under the window," "The man was sitting to the right of the women"), and temporal detail (information about when the event happened and explicit descriptions of the sequence of various events; e.g., "about two minutes later a women entered," "After no one replied, she left").

We used the Reality Monitoring (RM) definitions of all three detail categories because 
Running Head: Inoculating truth-tellers' memory as a function of encoding quality

(i) they are derived from research (Johnson \& Raye, 1981); (ii) are clearly articulated and well operationalised in the literature (Vrij, 2015); (iii) are used extensively in previous deception research (e.g. Harvey et al., 2017a; 2017b; 2019); and (iv) are considered reliable measures (Vrij, 2008). Total detail was calculated as the summation of all three categories (spatial, temporal and perceptual) into a single variable. The three sub-categories of detail were only introduced to facilitate (inter-rater) reliability coding. As no hypothesis was formulated about detail provided by sub-categories, we only report analysis using total detail.

A second coder (also blind to the veracity of the statements) coded a random selection of 30 statements $(20 \%)$ for all the dependent measures. Inter-rater reliabilities between the two coders for the occurrence frequency of perceptual, spatial, and temporal detail, as well as for accurate information, were measured via intra-class correlation coefficients (ICC). The ICC was high and therefore satisfactory for total spatial details [ICC $=.84]$, temporal details $[\mathrm{ICC}=.85]$, perceptual details $[\mathrm{ICC}=.90]$, and total details $[\mathrm{ICC}=.88]$. 
Running Head: Inoculating truth-tellers' memory as a function of encoding quality

\section{Results}

\section{Analysis Plan}

For parsimony we report Cohen's $f$ for all ANOVA effect sizes (whereby $f=0.1,0.25$, and 0.4 correspond to small, medium and large effects respectively; Cohen, 1988). Unlike Cohen's $d$, this index can be computed for the Veracity main effect, and Veracity x Initial interviewing interaction effect in the current study. Following recommendations (Cohen, 1988; Lakens, 2013), for all other contrasts we report Cohen's $d$ (with 95\% confidence intervals).

Unlike Null Hypothesis Significance Testing (NHST; for critiques, see Cohen, 1992; Cummings, 2014; Nickerson, 2000), Bayesian analysis provides a means of quantifying the extent to which the data support hypotheses (Wagenmakers et al., 2016; 2017a). To assess the strength of evidence, and in addition to significance testing, we also calculated a Bayes Factor (BF) score (e.g. Wagenmakers et al., 2016) using a default Bayesian $t$ test (with the default Cauchy's prior of 0.707; see Lakens, 2016) and open-source JASP software (https://jasp-stats.org see Wagenmakers et al., 2017b). BF 10 is the Bayes factor giving the evidence for alternative hypothesis over the null (and increases when evidence more strongly supports the alternative hypothesis). $\mathrm{BF}_{01}$ is the Bayes factor giving the evidence for the null hypothesis over the alternative (and increases when evidence more strongly supports the null hypothesis). Note: $\mathrm{BF}_{10}=1 / \mathrm{BF}_{01}$.

\section{Veracity Manipulation Checks}

We conducted three 3 (Veracity: Intentional encoding truth-tellers vs. Incidental encoding truth-tellers vs. Intentional liars) x 2 (Initial interviewing: Absent vs. present) between-subjects analyses of variance (ANOVAs) to examine interviewee's (i) estimated likelihood of receiving the reward; (ii) estimated likelihood of having to write a statement; and (iii) self-reported percentage of truthful information disclosed. We classify all three 
Running Head: Inoculating truth-tellers' memory as a function of encoding quality

measures as manipulation checks. Table 1 (below) shows the mean scores, standard deviations, and confidence intervals for the pre- and post-interview questionnaires, as a function of interviewee veracity.

[Table 1 about here]

A significant veracity main effect emerged for our first manipulation check (the estimated likelihood of receiving the reward), $F(2,146)=10.075, \mathrm{MSE}=12.806, p<0.001$, Cohen's $f=0.37$. Post hoc Tukey tests revealed that truth-tellers in the intentional encoding condition (henceforth, intentional truth-tellers) $(p=.009, d=.85,95 \% \mathrm{CI}[.43,1.25]), \mathrm{BF}_{10}=$ 6.774, and truth-tellers in the incidental encoding condition (henceforth, incidental truthtellers) $(p<.001, d=.56,95 \% \mathrm{CI}[.15, .95]), \mathrm{BF}_{10}=453.382$, estimated it more likely they would receive the reward than liars in the intentional encoding condition (henceforth, intentional liars). No difference emerged between intentional and incidental truth-tellers $(p=$ $.341, d=.32,95 \%$ CI $[-.08, .71]), \mathrm{BF}_{01}=1.598$.

A significant veracity main effect also emerged for our second manipulation check (the estimated likelihood of having to write a statement), $F(2,146)=15.369, \mathrm{MSE}=18.213, p<$ $0.001, f=0.46$. Post hoc Tukey tests showed that intentional liars estimated it more likely they would have to write a statement versus both intentional truth-tellers $(p<.001, d=.99$, $95 \% \mathrm{CI}[.56,1.39]), \mathrm{BF}_{10}=1942.286$, and incidental truth-tellers $(p<.001, d=.95,95 \% \mathrm{CI}$ $[.52,1.35]), \mathrm{BF}_{10}=3597.031$. No difference emerged between intentional and incidental truth-tellers $(p=.995, d=.03,95 \% \mathrm{CI}[-.36, .42]), \mathrm{BF}_{01}=4.766$.

A significant main of veracity effect emerged for our third manipulation check (the reported percentage of truthful information disclosed), $F(2,146)=617.472, \mathrm{MSE}=$ 71081.526, $p<0.001, f=2.01$. Post hoc Tukey tests revealed that for the social interaction, Intentional liars reported providing significantly less truthful information than either Intentional truth-tellers $(p<.001, d=5.27,95 \% \mathrm{CI}[4.37,6.01]), \mathrm{BF}_{10}=1.066 \times 10^{44}$, or 
Running Head: Inoculating truth-tellers' memory as a function of encoding quality

Incidental truth-tellers $(p<.001, d=5.59,95 \% \mathrm{CI}[4.65,6.36]), \mathrm{BF}_{10}=2.479 \times 10^{46 .}$ No

difference emerged between intentional and incidental truth-tellers $(p=.928, d=.09,95 \% \mathrm{CI}$

$[-.30, .48]), \mathrm{BF}_{01}=4.359$.

No significant main effects for Initial interviewing emerged for the estimated likelihood of receiving the reward, $F(1,146)=.141, p=.708, f=0.03, \mathrm{BF}_{01}=296.317$, the estimated likelihood of writing the statement, $F(1,146)=.666, p=.416, f=0.07, \mathrm{BF}_{01}=87957.426$, or for the percentage of truthful information disclosed, $F(1,146)=.090, p=.764, f=0.02, \mathrm{BF}_{01}$ $=4.869 \times 10^{69}$. Furthermore, no significant Veracity $\times$ Initial interviewing interaction effects emerged for the estimated likelihood of receiving the reward, $F(2,146)=.620, p=.539, f=$ $0.09, \mathrm{BF}_{01}=5.405$, the estimated likelihood of writing the statement, $F(2,146)=.722, p=$ $.487, f=0.10, \mathrm{BF}_{01}=4.361$, or for the percentage of truthful information disclosed, $F(2,146)$ $=1.623, p=.201, f=0.15, \mathrm{BF}_{01}=5.528$. Collectively, these findings support the validity of our veracity manipulation.

A logistic regression was performed to examine the effects of Veracity (Intentional truth-teller vs. Incidental truth-teller vs. Intentional liar) and Initial interviewing (Absent vs. present) on the participant's attention to either (i) just the video, or (ii) the video and social interaction. The logistic regression model was statistically significant $\chi^{2}(3)=79.726, p>$ .001 . The model explained $56.1 \%$ (Nagelkerke's $R^{2}$ ) of the variance of attention and correctly classified $86.2 \%$ of all cases $(77.8 \%$ of those attending towards just the video, and $90.8 \%$ of those attending towards the video and the social interaction). Incidental truth-tellers were .017 times $(95 \% \mathrm{CI}[.005, .061])$ less likely to attend to both the video and social interaction than Intentional liars $(p<.001)$. The difference between Intentional truth-tellers and Intentional liars was not significant $(p=.208)$. Initial interviewing was not a significant predictor $(p=.231)$. Collectively, these findings support the validity of the intentional and incidental encoding conditions within our veracity manipulation. 
Running Head: Inoculating truth-tellers' memory as a function of encoding quality

As a final manipulation check, an exploratory Bayesian independent groups $t$-test was conducted using the total number of details reported for the intelligence video by both intentional and incidental truth-tellers. Note: as the intelligence video element was included in the design to distract the truth-tellers in the incidental encoding condition (incidental truthtellers) from the real purpose of the experiment (the social interaction), all truth-tellers applied deliberate attention to the video. As such, we expected no differences to emerge between intentional and incidental truth-tellers in detail reported regarding the video. As expected, no difference in detail reported regarding the intelligence video emerged between Intentional truth-tellers $(M=44.34, S D=26.41,95 \% \mathrm{CI}[37.26,50.90])$ and incidental truthtellers $(M=42.10, S D=17.18,95 \%$ CI $[37.21,46.76]), t(98)=.503, p=.616$ (two-tailed),$d$ $=.10 .95 \% \mathrm{CI}[-.29, .49], \mathrm{BF}_{01}=4.238$. This indicates that the data was more than 4 times more likely to occur under null hypothesis than the alternative, corresponding to 'substantial' support for the null hypothesis. Thus, this finding supports the validity of our veracity manipulation.

\section{Motivation and preparation.}

We conducted two 3 (Veracity: Intentional truth-tellers vs. Incidental truth-tellers vs. Intentional liars) x 2 (Initial interviewing: Absent vs. present) between-subjects ANOVAs to examine interviewee's self-reported (i) motivation to appear convincing; and (ii) quality of preparation. Overall, interviewee's self-reported motivation was high (overall $M=6.41, S D=$ $0.99,95 \%$ CI $[6.25,6.56])$, with no main effects emerging for Veracity $F(2,146)=.290, p=$ $.748, f=0.06, \mathrm{BF}_{01}=11.916$, or Initial interviewing, $F(1,146)=.396, p=.530, f=0.05$, $\mathrm{BF}_{01}=4.735$. Additionally, the Veracity $\mathrm{x}$ Initial interviewing interaction effect was not significant, $F(2,146)=.083, p=.920, f=0.03, \mathrm{BF}_{01}=58.100$. Overall, interviewees rated the quality of their preparation as high (overall $M=5.18, S D=1.22,95 \%$ CI $[4.99,5.37]$ ), with no main effects emerging for Veracity, $F(2,146)=.188, p=.829, f=0.05, \mathrm{BF}_{01}=$ 
Running Head: Inoculating truth-tellers' memory as a function of encoding quality

12.936, or Initial interviewing, $F(1,146)=.080, p=.778, f=0.02, \mathrm{BF}_{01}=5.508$.

Furthermore, the Veracity $\mathrm{x}$ Initial interviewing interaction effect was not significant, $F(2$, $146)=1.764, p=.175, f=0.16, \mathrm{BF}_{01}=71.959$.

\section{Hypothesis Testing}

As stated previously, the briefing video was only included in the study to distract incidental truth-tellers. To create an incidental encoding condition, we required these truthtellers to believe that the study was about that video, and that the social interaction was unimportant (which is what they indeed thought; see logistic regression analysis above). Note, the attention manipulation was only related to the social interaction and not to the briefing video, as all truth-tellers (in both the intentional and incidental encoding conditions) were asked to pay close attention to the video. As such, we do not present the briefing video findings in this article and only report the findings for the social interaction. A full description of the briefing video findings is provided in the supplementary analysis section.

\section{Total details reported after delay}

We conducted a 3 (Veracity) $\times 2$ (Initial interviewing) ANOVA using total detail (disclosed in interviewee's statements three-weeks after the event) as the dependent variable. This analysis revealed a significant main effect for Initial interviewing, $F(1,146)=10.514$, $\mathrm{MSE}=36129.66, p=.001, f=0.27$. The main effect for Veracity was not significant, $F(2$, $146)=1.672, \mathrm{MSE}=5743.720, p=.192, f=0.15, \mathrm{BF}_{01}=74.159$. However, a significant Veracity $\mathrm{x}$ Initial interviewing interaction effect emerged, $F(2,146)=4.127, \mathrm{MSE}=$ $14182.938, p=.018, f=0.24$.

In terms of the Veracity $x$ Initial Interviewing interaction, as Table 2 shows, truthtellers in the intentional encoding condition reported significantly more total details in the initial interview-present condition than in the initial interview-absent condition. Additionally, truth-tellers in the incidental encoding condition reported significantly more total details in 
Running Head: Inoculating truth-tellers' memory as a function of encoding quality

the initial interview-present condition than in the initial interview-absent condition. Conversely, Intentional liars in the initial interview-present and absent interviewing conditions reported similar amounts of total detail. These results support Hypothesis 1.

As Table 2 (below) shows, the BF scores showed that in the initial interview-present (versus the initial interview-absent) condition, incidental encoding truth-tellers were approximately 2.5 times more likely to report more detailed statements, $\mathrm{BF}_{10}=2.457$. This corresponds to 'anecdotal' support for the alternative hypothesis (Lee \& Wagenmakers 2013). Furthermore, in the initial interview-present (versus the initial interview-absent) condition, intentional encoding truth-tellers were more than 35 times more likely to report more detailed statements, $\mathrm{BF}_{10}=35.210$. This corresponds to 'very strong' support for the alternative hypothesis. In contrast, no differences emerged between Intentional liars in the initial interview-present and Intentional liars in the initial interview absent condition, $\mathrm{BF}_{01}=$ 3.347. This indicates that the null hypothesis was more than 3 times more likely than the alternative, corresponding to 'substantial' support for the null hypothesis.

[Table 2 about here]

\section{Total details reported during initial interviewing}

To examine the quantity of detail reported during the initial interview, we conducted an exploratory Bayesian independent groups $t$-test on total detail reported by intentional and incidental truth-tellers. Intentional truth-tellers $(M=167.36, S D=73.60,95 \%$ CI $[136.98$, 197.74]) reported more detailed initial statements than incidental truth-tellers $(M=129.60$, $S D=36.25,95 \%$ CI $[114.64,144.56]), t(34.996)=2.301, p=.027$ (two-tailed),$d=.65 .95 \%$ CI $[.07,1.21], \mathrm{BF}_{10}=2.342$. This corresponds to 'anecdotal' support for the alternative hypothesis.

\section{Receiver Operator Characteristic (ROC) analysis}

To explore the utility of the richness-of-detail cue to correctly distinguish between 
Running Head: Inoculating truth-tellers' memory as a function of encoding quality genuine and deceptive statements, we conducted a series of four Receiver Operator Characteristic (ROC) analysis. We examined detail reported by intentional truth-tellers vs. intentional liars, and incidental truth-tellers vs. intentional liars, in the initial interview-absent and present condition separately. In accordance with the predictions derived from the richness-of-detail heuristic, in all cases the state variable (i.e. the particular dichotomous outcome a positive test - i.e. a higher score - indicates) was truth (i.e. incidental or intentional encoding truth-tellers). The Area Under the Curve (AUC) of a ROC curve (with 1- specificity, i.e. false positive rate, plotted on the $\mathrm{x}$-axis and sensitivity, i.e. true positive rate plotted on the y-axis) provides a measure of the diagnosticity of the criterion as a whole.

As Figures 1a-2b show, the area under the curve (AUC) obtained for reported detail was greater for intentional truth-tellers vs. intentional liars in the initial interview-present condition (.687) than the AUC's obtained in the initial interview-absent condition (.398), or for incidental truth-tellers vs intentional liars in the initial interview- present (.530) or absent condition (.368). This indicates superior diagnosticity for reported detail cue for intentional truth-tellers vs. intentional liars in the initial interview-present condition.

[Insert Figures $1 \mathrm{a}-2 \mathrm{~b}$ around here] 
Running Head: Inoculating truth-tellers' memory as a function of encoding quality

\section{Discussion}

The current study tested the hypotheses that (i) truth-tellers' incidentally and intentionally encoded memories could be inoculated from the effects of forgetting via initial interviewing, (ii) thus facilitating lie detection using the richness-of-detail cue. We found evidence supporting Hypothesis 1, and partial support for Hypothesis 2. Firstly, a dissociation emerged for the effects of initial interviewing on intentional liar's and truth-teller's statements provided three-weeks later: applying initial interviewing amplified truth-teller's later recall of incidentally and intentionally encoded information (however, not to the same extent), whereas intentional liar's delayed statements were unaffected. Secondly, intentional truth-tellers reported more detailed statements than intentional liars and were more accurately differentiated using the richness-of-detail cue in the initial interview-present than in the interview-absent condition.

Truth-tellers in the initial interview-present condition reported more details in delayed statements than truth-tellers in an initial interview-absent condition. This 'inoculation effect' induced via initial interviewing makes good theoretical sense and is consistent with the time critical nature of episodic memory (Anderson, 1983; Ayers et al., 1998; Wixted et al., 2007), and Associative Network models of memory performance (Anderson, 1976, 1983a, 1983b; Smith, 1998). As the effect sizes reported in Table 2 shows, the magnitude of the inoculation effect was greater for intentional truth-tellers $[d=.99]$ than for incidental truth-tellers $[d=$ .64]. This difference may be due to intentional traces enduring longer than incidental traces (Kontaxopoulou et al., 2017; Unsworth et al., 2010), facilitating the reporting of more compressively detailed initial statements. If initial interviewing inoculates subsequent recall (Ebbesen et al., 1998; Gabbert et al., 2012) specifically by preserving detail reported initially (Hope et al., 2014), and if intentional truth-tellers report more detailed initial statements (versus incidental truth-tellers), then intentional (versus incidental) truth-tellers should 
Running Head: Inoculating truth-tellers' memory as a function of encoding quality

display greater inoculation effects. Our data supported the above rationale, and therefore would appear to be consistent with the 'preservation-of-detail' explanation (see Hope et al., 2014).

As Table 2 shows, intentional liars' statements were, in respect to reported detail, insensitive to our initial interviewing manipulation. Intentional liars' observed insensitivity is consistent with previous research in two regards. First, liars do not rely exclusively upon their memory of an event (Vrij, 2008), and their statements are not constrained by successful retrieval (Harvey et al., 2017b; 2019). Unlike truth-tellers who rely on episodic memory originating from perceptual sources (Johnson \& Raye, 1981; Vrij, 2005; 2015), liars can supplement and/or replace true details they may forget - or wish to conceal - with outright fabricated detail originating from imagination (Harvey et al., 2019; Johnson et al., 1981; Nahari, 2018). Therefore, as liars' statements are not strictly limited by forgetting, inoculating their memory via initial interviewing may not necessarily amplify recall after a delay.

Second, liars only strategically simulate behaviours they perceive as typical of truthtellers (e.g. Köhnken, 1989, 1996, 2004). Memory is complex, and individuals may not comprehend its multiple facets (Legaut \& Laurence, 2007; Ost et al., 2015; Simons \& Chabris, 2011). For example, truth-tellers typically display reminiscence (Gilbert \& Fisher, 2006), i.e. reporting previously unrecalled details during successive recall attempts. However, liars do not correctly simulate this pattern (Colwell et al., 2007; 2013; Hinds et al., 2010). Additionally, individuals frequently display erroneous metacognition, especially regarding judgements about memory processes (Koriat et al., 2004; Kornell et al., 2009). Our intentional liars may have therefore failed to correctly estimate the appropriate quantity of detail to disclose in response to initial interviewing after a delay (Harvey et al., 2019). In 
Running Head: Inoculating truth-tellers' memory as a function of encoding quality

sum, intentional liars may have been unaware of, or failed to correctly simulate, the inoculating effects of initial interviewing on subsequent recall.

Overall, our data highlights the difficulty of using richness-of-detail in delayed interviewing paradigms, especially for contexts in which truth-tellers encode information incidentally. Although researchers have begun exploring lie-detection in delayed interviewing paradigms (Harvey et al., 2017a; 2019; Izotovas et al., 2018; Nahari, 2018), most deception research does not examine incidental encoding truth-tellers (Harvey et al., 2017b), despite incidental encoding being most common in real-life settings (Kontaxopoulou et al., 2017).

Regarding the performance of the richness-of-detail cue, the area under the curve (AUC) obtained for reported detail was greater for intentional truth-tellers vs. intentional liars in the initial interview-present condition (.687) than the AUC's obtained in the initial interview-absent condition (.398), or for incidental truth-tellers vs intentional liars in the initial interview- present (.530) or the interview-absent condition (.368). This indicates superior diagnosticity for reported detail cue for intentional truth-tellers vs. intentional liars in the initial interview-present condition. In fact, it was only in this condition that truth tellers and liars could be classified above chance levels when using the reporting details cue. It appears the utility of the 'richness-of-detail' cue has boundary conditions and is clearly diminished in sub-optimal memorial contexts (i.e. after delays and when truth-tellers encode information incidentally; also see Harvey et al. 2017a; 2017b; 2019). Accordingly, facilitating (and amplifying) the delayed recall of incidentally encoded memories is of both theoretical and applied importance. Future research should explore this possibility.

Methodologically, the inoculation effect observed (especially for incidental truthtellers) may have been limited by our initial interview protocol's lack of cognitive mnemonics (c.f. the Cognitive Interview, Fisher \& Gieselman, 1992). Incidental truth-tellers 
Running Head: Inoculating truth-tellers' memory as a function of encoding quality

(who have less enduring episodic memory trace compared to intentional truth-tellers) may have reported more detailed initial statements if provided additional retrieval support. Importantly, high-quality initial interviewing appears to inoculate subsequent memory performance specifically via preserving details recalled initially (Hope et al., 2014). Therefore, eliciting even more exhaustive and elaborative recall during initial interviewing (Gabbert, Hope \& Fisher, 2009; Gabbert, Hope, Fisher, Jamieson, 2012; Hope, Gabbert \& Fisher, 2011) may magnify the inoculation effect for truth-tellers generally, and incidental truth-tellers specifically. Research should explore this possibility.

The attention manipulation and veracity condition were not themselves orthogonally manipulated in this study, as this would have resulted in an addition incidental liar condition (i.e., individuals lying about events they did not attend to during encoding). This aspect was not examined in the current study, or in previous research (e.g. Harvey et al., 2017b). However, such incidental lying may occur in the real-world (i.e. distracted witnesses that decide to lie after an event to protect a suspect). Future research should explore this possibility.

Finally, the effect of our encoding manipulation upon interviewee's verbal output should be interpreted within the context of the experiment. The small differences in terms of reported detail between intentional truth-tellers, incidental truth-tellers and intentional liars (in both the initial interview-present, and absent conditions) could be considered artifacts of the experimental task. The social interaction that the truth-tellers in the intentional condition experienced and discussed was of a short duration and of no real importance to them (outside of the experimental scenario), whereas truth-tellers in the incidental condition had no reason to attend to the interaction at all. It is plausible different findings will emerge when truthtellers discuss rich events in the past that held genuine importance to them (Harvey et al., 2017b). For example, when truth-tellers and liars discussed a holiday trip they made in the 
Running Head: Inoculating truth-tellers' memory as a function of encoding quality past year, truth-tellers were more detailed than liars who made up a story about such a trip (Vrij et al., 2017). However, the general principle that inoculating truth-tellers memory facilitates more detailed reporting after delays, and thus amplifies lie-detection performance using the richness-of-detail cue, also applies to richer and more important events.

Furthermore, because our results are based upon theoretical memory principles, they appear equally applicable to interviews of suspects (modeled by intentional liars in the current study) and witnesses (modelled by intentional and incidental truth-tellers).

In conclusion, and consistent with associative network models (Anderson, 1983), initial interviewing inoculated truth-tellers memory from the effects of forgetting, facilitating the reporting of more detailed statements three weeks later. Extending previous memory research (Hope et al., 2014), the inoculation effect was more pronounced for truth-tellers who encoded information intentionally rather than incidentally. Initial interviewing has no effect on intentional liars' statements. Accordingly, and extending previous deception research (Izotovas et al., 2018; Nahari, 2018), more intentional liars and intentional truth-tellers were correctly distinguished the using richness-of-detail cue in the initial interview-present than in the initial interview- absent condition. In contrast, initial interviewing did not facilitate improved classification of intentional liars and incidental truth-tellers using the richness-ofdetail cue. Therefore, in delayed interviewing paradigms where truth-tellers encode information intentionally (rather than incidentally), lie-detection performance using the richness-of-detail cue may be amplified via initial interviewing. 
Running Head: Inoculating truth-tellers' memory as a function of encoding quality

\section{References}

Amado, B. G., Arce, R., Farina, F., \& Vilariño, M. (2016). Criteria-Based Content Analysis (CBCA) reality criteria in adults: A meta-analytic review. International Journal of Clinical and Health Psychology, 16(2), 201-210. DOI: 10.1016/j.ijchp.2016.01.002

Anderson, J. R. (1976). Language, memory, and thought. Hillsdale, NJ: Erlbaum.

Anderson, J. R. (1983). A spreading activation theory of memory. Journal of Verbal Learning and Verbal Behavior, 22, 261-295. doi:10.1016/S0022-5371(83)90201-3

Anderson, J. R. (1983). The architecture of cognition. Hillsdale, NJ: Erlbaum.

Ayers, M. S. \& Reder, L. M. (1998). A theoretical review of the misinformation effect: Predictions from an activation-based memory model. Psychonomic Bulletin \& Review, 5 (1), 1-21. DOI: 10.3758/BF03209454

Bjork, R. A. (1988). Retrieval practice and the maintenance of knowledge. In M. M. Gruneberg, P.

E. Morris \& R. N. Skyes (Eds.), Practical aspects of memory: Current research and issues:

Vo. 1. Memory in everyday life (pp. 396-401). New York: Wiley.

British Psychological Society (2009). Code of Ethics and Conduct. Guidance by the Ethics Committee of the British Psychological Society. Leicester, UK: British Psychological Society.

British Psychological Society (2014). Code of Ethics and Conduct. Guidance by the Ethics Committee of the British Psychological Society. Leicester, UK: British Psychological Society.

British Psychological Society (2018). Code of Ethics and Conduct. Guidance by the Ethics Committee of the British Psychological Society. Leicester, UK: British Psychological Society. 
Running Head: Inoculating truth-tellers' memory as a function of encoding quality

Cohen, J. (1988). Statistical power analysis for the behavioral sciences (2nd ed.). Hillsdale, NJ: Erlbaum.

Cohen, J. (1992). A power primer. Psychological bulletin, 112(1), 155-159.

Colwell, K., Fede, J., \& Hiscock-Anisman, C. (2013). Assessment Criteria Indicative of Deception: an example of the new paradigm of differential recall enhancement. In B.S. Cooper et al. (Eds.) Applied Issues in Investigative Interviewing, Eyewitness Memory, and Credibility Assessments. New York: Springer Science and Business Media.

Colwell, K., Hiscock-Anisman, C. K., Memon, A., Taylor, L., \& Prewett, J. (2007). Assessment Criteria Indicative of Deception (ACID): An integrated system of investigative interviewing and detecting deception. Journal of Investigative Psychology and Offender Profiling, 4(3), 167-180, DOI: 10.1002/jip.73

Craik, F. I., \& Tulving, E. (1975). Depth of processing and the retention of words in episodic memory. Journal of experimental Psychology: general, 104(3), 268. DOI: 10.1037/00963445.104.3.268

Craik, F. I., Govoni, R., Naveh-Benjamin, M., \& Anderson, N. D. (1996). The effects of divided attention on encoding and retrieval processes in human memory. Journal of Experimental Psychology: General, 125(2), 159-180.

Cumming, G. (2014). The new statistics: Why and how. Psychological science, 25(1), 7-29, DOI: $10.1177 / 0956797613504966$

Damasio, A. R. (1989). Time-locked multiregional retroactivation: A systems-level proposal for the neural substrates of recall and recognition. Cognition, 33(1-2), 25-62.

Dempster, F.N. (1996). Distributing and managing the conditions of encoding and practice. In E.L. Bjork \& R.A. Bjork (Eds.), Human memory (pp. 197-236). San Diego, CA: Academic Press. DePalo, B. M., Lindsay, J. J., Malone, B. E., Muhlenbruck, L., Charlton, K., \& Cooper, H. (2003). Cues to deception. Psychological bulletin, 129(1), 74-118. DOI:10.1037/0033-2909.129.1.74 
Running Head: Inoculating truth-tellers' memory as a function of encoding quality

Ebbesen, E. B., \& Rienick, C. B. (1998). Retention interval and eyewitness memory for events and personal identifying attributes. Journal of Applied Psychology, 83(5), 745-762.

Ebbinghaus, H. (1885). Memory: A contribution to experimental psychology. Leipzig: Duncker \& Humblot.

Ewens, S., Vrij, A., Jang, M., \& Jo, E. (2014). Drop the small talk when establishing baseline behaviour in interviews. Journal of Investigative Psychology and Offender Profiling, 11(3), 244-252. DOI: 10.1002/acp.3196

Ewens, S., Vrij, A., Mann, S., \& Leal, S. (2015). Using the Reverse Order Technique with NonNative Speakers or Through an Interpreter. Applied Cognitive Psychology. DOI: 10.1002/acp.3196

Faul, ., Erdfelder, E., Buchner, A., \& Lang, A. G. (2009). Statistical power analyses using G* Power 3.1: Tests for correlation and regression analyses. Behavior research methods, 41(4), 11491160. https://doi.org/10.3758/BRM.41.4.1149

Faul, ., Erdfelder, E., Lang, A. G., \& Buchner, A. (2007). G* Power 3: A flexible statistical power analysis program for the social, behavioral, and biomedical sciences. Behavior research methods, 39(2), 175-191. https://doi.org/10.3758/BF03193146

Fisher, R. E (1996). Implications of output-bound measures for laboratory and field research in memory. Behavioral and Brain Sciences, 19, 197.

Gabbert, F., Hope, L., \& Fisher, R. P. (2009). Protecting eyewitness evidence: Examining the efficacy of a self-administered interview tool. Law and human behavior, 33(4), 298-307. DOI:10.1007/s10979-008-9146-8

Gabbet, F., Hope, L., Fisher, R. P., \& Jamieson, K. (2012). Protecting against misleading post-event information with a self-administered interview. Applied Cognitive Psychology, 26(4), 568575. http://dx.doi.org/10.1002/acp.2828 
Running Head: Inoculating truth-tellers' memory as a function of encoding quality

Goldsith, M., Koriat, A., \& Pansky, A. (2005). Strategic regulation of grain size in memory reporting over time. Journal of Memory and Language, 52(4), 505-525. doi:10.1016/j.jml.2005.01.010

Harvey, A. C., Vrij, A., Hope, L., Leal, S., \& Mann, S. (2017a). A Stability Bias Effect Among Deceivers. Law and human behavior. DOI:10.1037/lhb0000258.

Harvey, A. C., Vrij, A., Leal, S., Hope, L., \& Mann, S. (2017b). Deception and Decay: Verbal Lie Detection as a Function of Delay and Encoding Quality. Journal of Applied Research in Memory and Cognition. https://doi.org/10.1016/j.jarmac.2017.04.002

Harvey, A. C., Vrij, A., Leal, S., Hope, L., \& Mann, S. (2019). Amplifying deceivers' flawed metacognition: Encouraging disclosures after delays with a model statement. Acta Psychologica, 200. https://doi.org/10.1016/j.actpsy.2019.102935

Hines, A., Colwell, K., Hiscock-Anisman, C., Garrett, E., Ansarra, R., Montalvo, L., 2010. Impression management strategies of deceivers and honest reporters in an investigative interview. European Journal of Psychology Applied to Legal Context, 2, 73-90.

Hope, L., Gabbert, F., \& Fisher, R. P. (2011). From laboratory to the street: Capturing witness memory using the Self-Administered Interview. Legal and criminological psychology, 16(2), 211-226. https://doi.org/10.1111/j.2044-8333.2011.02015.x

Hope, L., Gabbert, F., Fisher, R. P., \& Jamieson, K. (2014). Protecting and enhancing eyewitness memory: The impact of an initial recall attempt on performance in an investigative interview. Applied Cognitive Psychology, 28(3), 304-313. DOI: 10.1002/acp.2984

Izotovs, A., Vrij, A., Hope, L., Mann, S., Granhag, P. A., \& Strömwall, L. A. (2018). Facilitating memory-based lie detection in immediate and delayed interviewing: The role of mnemonics. Applied Cognitive Psychology, 32(5), 561-574. DOI: 10.1002/acp.3435

Johnson, M. K., \& Raye, C. L. (1981). Reality monitoring. Psychological review, 88(1), 67-85, doi: $10.1037 / / 0033-295 X .88 .1 .67$ 
Running Head: Inoculating truth-tellers' memory as a function of encoding quality

Kebbel, M. R., Milne, R., \& Wagstaff, G. F. (1999). The cognitive interview: A survey of its forensic effectiveness. Psychology, crime and law, 5(1-2), 101-115.

https://doi.org/10.1080/10683169908414996

Kebbell, M. R., Wagstaff, G. F., \& Covey, J. A. (1996). The influence of item difficulty on the relationship between eyewitness confidence and accuracy. British Journal of Psychology, 87(4), 653-662.

Köhnken, G. (1989). Behavioral correlates of statement credibility: Theories, paradigms and results. In H. Wegener, F. Lösel, \& J. Haisch (Eds.), Criminal behavior and the justice system: Psychological perspectives (pp. 271-289). New York, NY: Springer-Verlag.

Köhnken, G. (1996). Social psychology and the law. In G. R. Semin \& K. Fiedler (Eds.), Applied social psychology (pp. 257-282). London, Great Britain: Sage.

Köhnken, G. (2004). Statement validity analysis and the 'detection of the truth'. In P. A. Granhag \& L. A. Strömwall (Eds.), Deception detection in forensic contexts (pp. 41-63). Cambridge, England: Cambridge University Press.

Kontaopoulou, D., Beratis, I. N., Fragkiadaki, S., Pavlou, D., Yannis, G., Economou, A., ... \& Papageorgiou, S. G. (2017). Incidental and intentional memory: their relation with attention and executive functions. Archives of Clinical Neuropsychology, 32(5), 519-532. https://doi.org/10.1093/arclin/acx027

Koriat, A., Bjork, R. A., Sheffer, L., \& Bar, S. K. (2004). Predicting one's own forgetting: The role of expereicne-based and theory-based processes. Journal of Experimental Psychology: General, 133, 4, 643-656. DOI: 10.1037/0096-3445.133.4.643.

Koriat,A., Levy-Sadot, R., Edry, E., \& de Marcas, S. (2003). What do we know about what we cannot remember? Accessing the semantic attributes of words that cannot be recalled. Journal of Experimental Psychology: Learning, Memory, and Cognition, 29(6), 1095-1105. DOI: 10.1037/0278-7393.29.6.1095 
Running Head: Inoculating truth-tellers' memory as a function of encoding quality

Kornell, N., \& Bjork, R. A. (2009). A stability bias in human memory: overestimating remembering and underestimating learning. Journal of Experimental Psychology: General, 138(4), 449. DOI: $10.1037 / \mathrm{a} 0017350$

Krix, A. C., Sauerland, M., Gabbert, F., \& Hope, L. (2014). Providing eyewitnesses with initial retrieval support: What works at immediate and subsequent recall?. Psychology, Crime \& Law, 20(10), 1005-1027. https://doi.org/10.1080/1068316X.2014.902456

Lakens, D. (2013). Calculating and reporting effect sizes to facilitate cumulative science: A practical primer for t-tests and ANOVAs. Frontiers in Psychology, 4. doi:10.3389/fpsyg.2013.00863

Lakens, D. (2016). Power analysis for default Bayesian t-tests. [blog post]. Retrieved from https://daniellakens.blogspot.com/2016/01/power-analysis-for-default-bayesian-t.html.

Lee, M. D., \& Wagenmakers, E. J. (2013). Bayesian data analysis for cognitive science: A practical course. New York, NY: Cambridge University Press.

Legault, E., \& Laurence, J. R. (2007). Recovered memories of childhood sexual abuse: Social worker, psychologist, and psychiatrist reports of beliefs, practices, and cases. Australian Journal of Clinical and Experimental Hypnosis, 35, 111-133.

Leins, D., Fisher, R. P., \& Ross, S. J. (2013). Exploring liars'strategies for creating deceptive reports. Legal and Criminological Psychology, 18, 141-151. DOI: 10.1111/j.20448333.2011.02041.x

Masip, J., Sporer, S. L., Garrido, E., \& Herrero, C. (2005). The detection of deception with the reality monitoring approach: A review of the empirical evidence. Psychology, Crime \& Law, 11(1), 99-122. http://dx.doi.org/10.1080/10683160410001726356

Mulligan, N. W. (1998). The role of attention during encoding in implicit and explicit memory. Journal of Experimental Psychology: Learning, Memory, and Cognition, 24(1), 2747.http://dx.doi.org/10.1037/0278-7393.24.1.27 
Running Head: Inoculating truth-tellers' memory as a function of encoding quality

Mulligan, N.W. (2003). Effects of cross modal and intra modal division of attention on perceptual implicit memory. Journal of Experimental Psychology: Learning, Memory, and Cognition, 29(2), 262. http://dx.doi.org/10.1037/0278-7393.29.2.262

Murre J., \& Dros J. (2015). Replication and analysis of Ebbinghaus' forgetting curve. PLoS One, 10:e0120644 10.1371/journal.pone.0120644

Nahari G. (2018). Reality monitoring in the forensic context: Digging deeper into the speech of liars. Journal of Applied Research in Memory and Cognition, 7(3), 432-440.

https://doi.org/10.1016/j.jarmac.2018.04.003

Nahari G., \& Pazuelo, M. (2015). Telling a convincing story: Richness in detail as a function of gender and information. Journal of applied research in memory and cognition, 4(4), 363-367, https://doi.org/10.1016/j.jarmac.2015.08.005

Nahari, G., \& Ben-Shakhar, G. (2011). Psychophysiological and behavioral measures for detecting concealed information: The role of memory for crime details. Psychophysiology, 48(6), 733744, DOI: $10.1111 / \mathrm{j} .1469-8986.2010 .01148 . x$

Nahari, G., \& Vrij, A. (2015). Systematic errors (biases) in applying verbal lie detection tools: richness in detail as a test case. Crime Psychology Review, 1(1), 98-107, https://doi.org/10.1080/23744006.2016.1158509 neural substrates of recall and recognition. Cognition, 33, 25-62.

Nickerson, R. S. (2000). Null hypothesis significance testing: a review of an old and continuing controversy. Psychological methods, 5(2), 241-301

Oberlader, V. A., Naefgen, C., Koppehele-Goseel, J., Quinten, L., Banse, R., \& Schmidt, A. F. (2016). Validity of Content-Based Techniques to Distinguish True and Fabricated Statements: A Meta-Analysis. Law and human behavior. DOI: $\underline{10.1037 / 1 \mathrm{hb} 0000193}$ 
Running Head: Inoculating truth-tellers' memory as a function of encoding quality

Ost, J., Easton, S., Hope, L., French, C. C., \& Wright, D. B. (2015). Latent variables underlying the memory beliefs of Chartered Clinical Psychologists, Hypnotherapists and undergraduate students. Memory, 1-12. https://doi.org/10.1080/09658211.2015.1125927

Penrod, S. D., Loftus, E. F., \& Winkler, J. (1982). The reliability of eyewitness testimony: A psychological perspective. The psychology of the courtroom, 119-168. pp. 317-344). San Diego: Academic Press.

Reyna, V. F., \& Kiernan, B. (1994). Development of gist versus verbatim memory in sentence recognition: Effects of lexical familiarity, semantic content, encoding instructions, and retention interval. Developmental Psychology, 30(2), 178-191.

Roedier III, H. L., \& Karpicke, J. D. (2006). The power of testing memory: Basic research and implications for educational practice. Perspectives on psychological science, 1(3), 181-210. https://doi.org/10.1111/j.1745-6916.2006.00012.x

Roediger III, H. L., \& Karpicke, J. D. (2006). Test-enhanced learning: Taking memory tests improves long-term retention. Psychological science, 17(3), 249-255. https://doi.org/10.1111/j.1467-9280.2006.01693.x

Roediger, H. L., \& Butler, A. C. (2011). The critical role of retrieval practice in long-term retention. Trends in cognitive sciences, 15(1), 20-27, https://doi.org/10.1016/j.tics.2010.09.003

Sauer, J., \& Hope, L. (2016). The effects of divided attention at study and reporting procedure on regulation and monitoring for episodic recall. Acta psychologica, 169, 143-156. http://dx.doi.org/10.1016/j.actpsy.2016.05.015

Shaw, D. J., Vrij, A., Leal, S., Mann, S., Hillman, J., Granhag, P. A., \& Fisher, R. P. (2013). Expect the unexpected? Variations in question type elicit cues to deception in joint interviewer contexts. Applied Cognitive Psychology, 27(3), 336-343. DOI: 10.1002/acp.2911 
Running Head: Inoculating truth-tellers' memory as a function of encoding quality

Simons, D. J., \& Chabris, C. F. (2011). What people believe about how memory works: A representative survey of the U.S. population. PLoS ONE, 6, e22757. http://dx.doi.org/10.1371/journal.pone.0022757

Smith, E. R. (1998). Mental representation and memory, in The handbook of social psychology, eds D.T. Fiske, and G. Lindzey (Boston, MA: McGraw-Hill), 391-445.

Tulving, E. (1972). Episodic and semantic memory. Organization of memory, 1, 381-403.

Tulving, E. (1993). What is episodic memory?. Current directions in psychological science, 2(3), 6770.

Unswoth, N., \& Spillers, G. J. (2010). Variation in working memory capacity and episodic recall: The contributions of strategic encoding and contextual retrieval. Psychonomic Bulletin \& Review, 17(2),200-205. doi:10.3758/PBR.17.2.200

Vrij, A (2016). Baselining as a lie detection method. Applied Cognitive Psychology, 30(6), 11121119. https://doi.org/10.1002/acp.3288

Vrij, A. (2005). Criteria-Based Content Analysis: A Qualitative Review of the First 37 Studies. Psychology, Public Policy, and Law, 11(1), 3-41. DOI: 10.1037/1076-8971.11.1.3

Vrij, A. (2008). Detecting lies and deceit: Pitfalls and opportunities. Chichester, UK: John Wiley \& Sons.

Vrij, A. (2015). Verbal Lie Detection tools: Statement validity analysis, reality monitoring and scientific content analysis. In P. A. Granhag, A. Vrij, \& B. Verschuere. (Eds.) Detecting Deception Current Challenges and Cognitive Approaches. Chichester: John Wiley \& Sons.

Vrij, A., Leal, S., Mann, S., Dalton, G., Jo, E., Shaboltas, A., ... \& Houston, K. (2017). Using the Model Statement to elicit information and cues to deceit in interpreter-based interviews. Acta psychologica, 177, 44-53, https://doi.org/10.1016/j.actpsy.2017.04.011 
Running Head: Inoculating truth-tellers' memory as a function of encoding quality

Wagenmakers, E. J., Love, J., Marsman, M., Jamil, T., Ly, A., Verhagen, J., ... \& Meerhoff, F. (2017). Bayesian inference for psychology. Part II: Example applications with JASP. Psychonomic Bulletin \& Review, 1-19, https://doi.org/10.3758/s13423-017-1323-7

Wagenmakers, E. J., Marsman, M., Jamil, T., Ly, A., Verhagen, J., Love, J., ... \& Matzke, D. (2017). Bayesian inference for psychology. Part I: Theoretical advantages and practical ramifications. Psychonomic bulletin \& review, 1-23, https://doi.org/10.3758/s13423-017$1343-3$

Wagenmakers, E. J., Morey, R. D., \& Lee, M. D. (2016). Bayesian benefits for the pragmatic researcher. Current Directions in Psychological Science, 25(3), 169-176, doi: $10.1177 / 0963721416643289$

Wagenmakers, E. J., Wetzels, R., Borsboom, D., \& van der Maas, H. L. J. (2011). Why psychologists must change the way they analyze their data: The case of psi. Journal of Personality and Social Psychology, 100, 426-432. DOI: 10.1037/a0022790

Wixted, J. \& Ebbesen, E. B. (1997). Genuine power curves in forgetting: Quantitative analysis of individual subject forgetting functions. Memory \& Cognition, 23, 731-739. DOI: 10.3758/BF03211316.

Wixted, J. T., \& Carpenter, S. K. (2007). The Wickelgren power law and the Ebbinghaus savings function. Psychological Science, 18(2), 133-134. DOI: 10.1111/j.1467-9280.2007.01862.x 
Running Head: Inoculating truth-tellers' memory as a function of encoding quality

\section{Table 1.}

Descriptive statistics for pre-interview and post-interview questionnaire responses, as a function of interviewee veracity

\begin{tabular}{|c|c|c|c|c|c|c|c|c|c|}
\hline \multirow[t]{2}{*}{ Measure } & \multicolumn{3}{|c|}{ Intentional truth-tellers } & \multicolumn{3}{|c|}{ Incidental truth-tellers } & \multicolumn{3}{|c|}{ Intentional liars } \\
\hline & $\mathrm{M}$ & $S D$ & $95 \% \mathrm{CI}$ & $M$ & $S D$ & $95 \% \mathrm{CI}$ & $M$ & $S D$ & $95 \% \mathrm{CI}$ \\
\hline Motivation & $6.35^{\mathrm{a}}$ & 1.21 & {$[5.96,6.66]$} & $6.39^{\mathrm{a}}$ & .90 & {$[6.14,6.63]$} & $6.50^{\mathrm{a}}$ & .81 & {$[6.26,6.72]$} \\
\hline Preparation $^{\mathrm{a}}$ & $5.26^{\mathrm{a}}$ & 1.15 & {$[4.97,5.57]$} & $5.18^{\mathrm{a}}$ & 1.24 & {$[4.84,5.51]$} & $5.11^{\mathrm{a}}$ & 1.29 & {$[4.74,5.44]$} \\
\hline Likelihood of receiving reward/credits & $5.47^{\mathrm{a}}$ & 1.05 & {$[5.16,5.78]$} & $5.78^{\mathrm{a}}$ & .97 & {$[5.48,6.10]$} & $4.80^{\mathrm{b}}$ & 1.32 & {$[4.42,5.16]$} \\
\hline Likelihood of writing a statement & $2.50^{\mathrm{a}}$ & 1.05 & {$[2.19,2.81]$} & $2.53^{\mathrm{a}}$ & 1.08 & {$[2.25,2.86]$} & $3.58^{\mathrm{b}}$ & 1.13 & {$[3.24,3.90]$} \\
\hline Extent of truthfulness (percentage) & $94.12^{\mathrm{a}}$ & 9.42 & {$[91.27,96.67]$} & $94.90^{\mathrm{a}}$ & 7.84 & {$[92.73,96.95]$} & $29.40^{\mathrm{b}}$ & 14.06 & {$[25.33,33.27]$} \\
\hline
\end{tabular}

Note: ${ }^{\text {ab }}$ superscripts denote significant differences $(p<.05)$ between veracity conditions (only cells with different superscripts differ significantly).

${ }^{\text {a }}$ Preparation was calculated by clustering four self-reported 7-point Likert scale responses; (i) quality of preparation; (ii) usefulness of preparation; (iii) sufficiency of preparation; and (iv) completeness of preparation, into a single variable (Cronbach's alpha $=.91$ ). 
Running Head: Inoculating truth-tellers' memory as a function of encoding quality

Table 2.

Total detail reported during the delayed interview, as a function of Veracity and Initial interviewing.

$$
\text { Mean }(S D) \text { total details reported }
$$

\begin{tabular}{lccccc} 
Veracity & Initial interview-absent & Initial interview-present & $t$ & $p$ & Cohen's $d$ \\
\hline Intentional truth-tellers & $99.12(49.09)$ & $161.96(75.14)$ & 3.550 & $.001 * *$ & $.99,95 \% \mathrm{CI}[.40,1.56]$ \\
Incidental truth-tellers & $92.88(43.32)$ & $126.60(59.16)$ & 2.329 & $.024 *$ & $.64,95 \% \mathrm{CI}[.08,1.21]$ \\
Intentional liars & $125.88(63.74)$ & $121.84(63.74)$ & .237 & .814 & $.07,95 \% \mathrm{CI}[-.49, .62]$
\end{tabular}

$* p<0.05 . * * p<0.01 . * * * p<.001$ 
Running Head: Inoculating truth-tellers' memory as a function of encoding quality

Figure captions

Figure 1a: ROC curve (with AUC) for reported detail by intentional truth-tellers and intentional liars, in the initial interview-present condition.

Figure 1b: ROC curve (with AUC) for reported detail by intentional truth-tellers and intentional liars, in the initial interview-absent condition.

Figure 2a: ROC curve (with AUC) for reported detail by incidental truth-tellers and intentional liars, in the initial interview-present condition.

Figure 2b: ROC curve (with AUC) for reported detail by incidental truth-tellers and intentional liars, in the initial interview-absent condition. 
Running Head: Inoculating truth-tellers' memory as a function of encoding quality

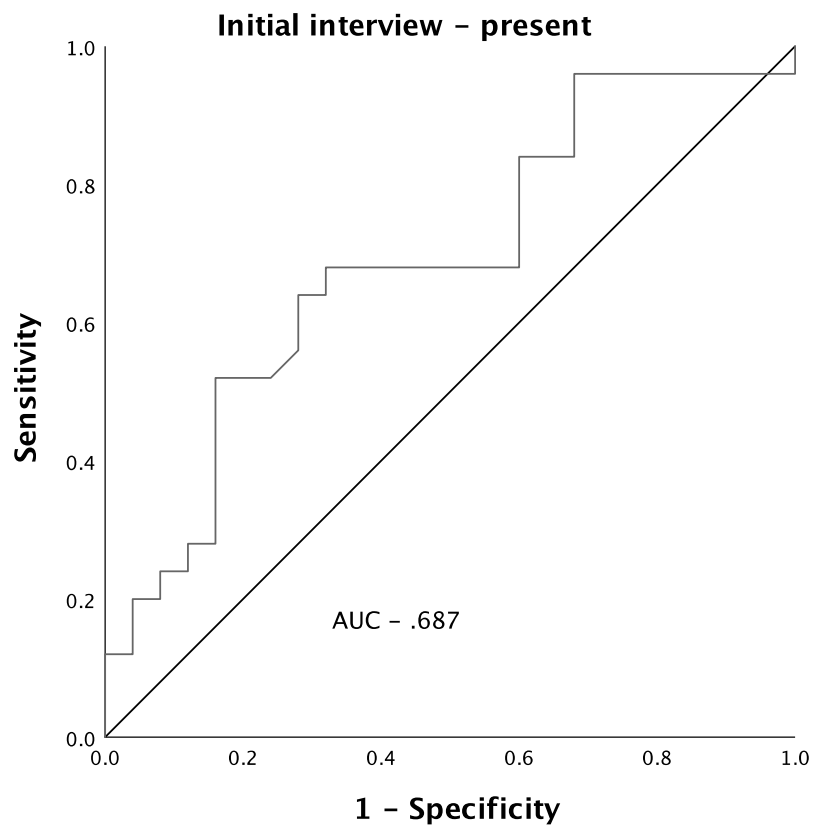

Figure 1a

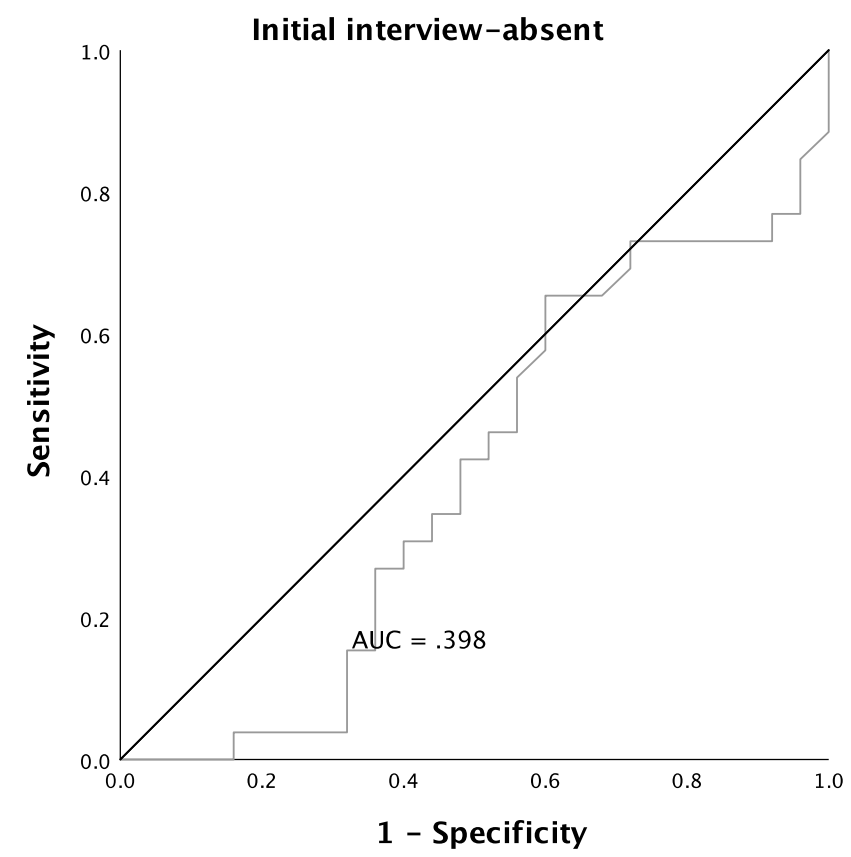

Figure $1 b$ 
Running Head: Inoculating truth-tellers' memory as a function of encoding quality

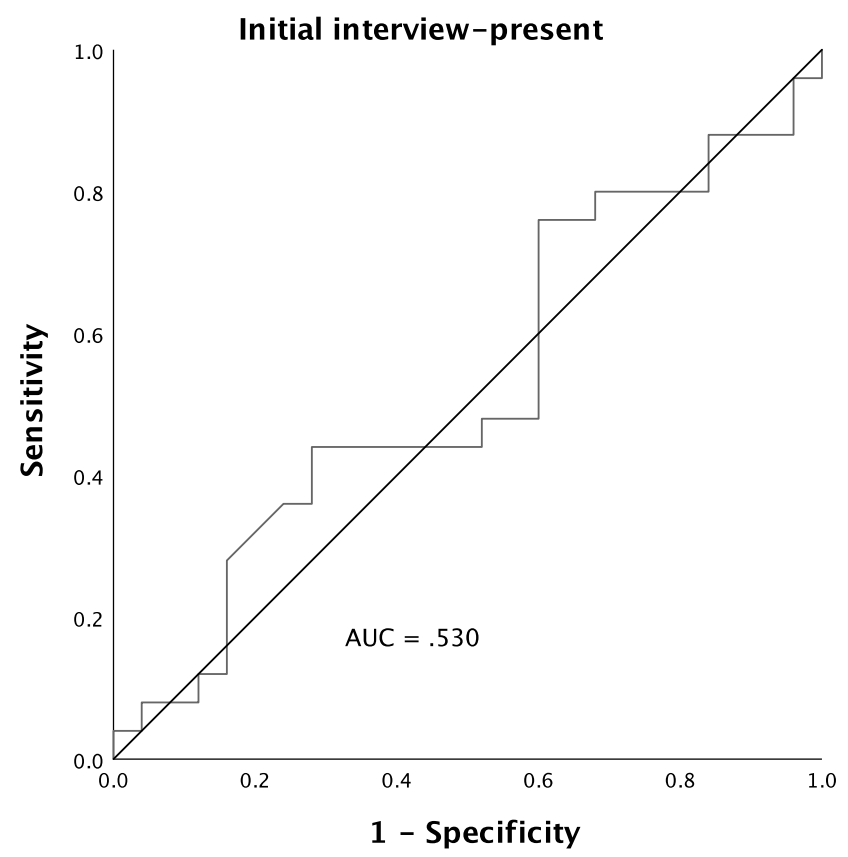

Figure 2a

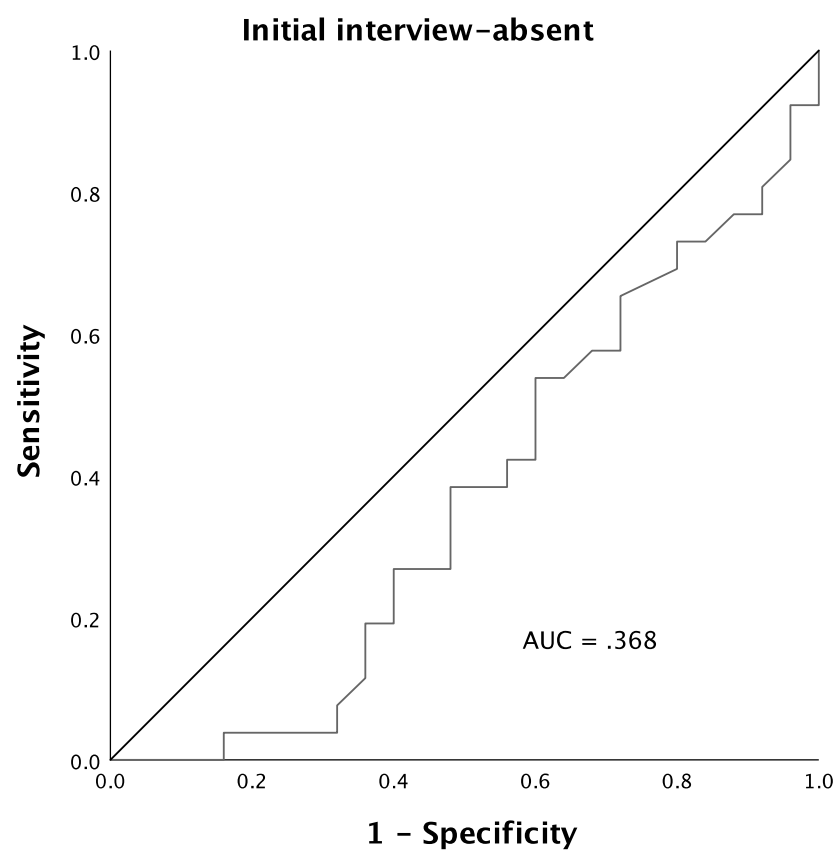

Figure $2 b$ 
Running Head: Inoculating truth-tellers' memory as a function of encoding quality

APPENDIX 1. Social exchange in the waiting room script

Once the participant enters the waiting room they will find another participant already sat there, in reality it will be a confederate B (CB). After one minute another participant (confederate A, CA) enters the room and an exchange between the two confederates will occur, their conversation will be briefly interrupted by another confederate (confederate $\mathrm{C}$, $\mathrm{CC})$ as follows:

CA) "Hiya, how are you?"

CB) "Ah not too bad thanks you?"

CA) "Yeah all good, are you still doing chemistry? I haven’t seen you for a while."

CB) "No I do physics so I only share the 'thermodynamics' module from chemistry"

CA) “Oh, that's why then, I was ill and missed the last lecture on that ...don't suppose you have notes do you?"

CB) "Yeah sure, in fact I may have them here (rummages in bag) but I'll need them back? (At this point confederate $\mathrm{C}$ enters, looks around the room and says “ $\mathrm{Oh}$ I'm sorry I was looking for Zarah, I'll see if she's in the other lab" and then leaves) CB continues talking "Perhaps you can photo copy them after this?" Finds and gives notes to CA.

CA) Great! Thanks, I'll photocopy them as soon as I've finished this and bring them back to you is that $\mathrm{OK}$ ?

CB) Yeah fine 
Running Head: Inoculating truth-tellers' memory as a function of encoding quality

APPENDIX 2. Interview protocol script

1. Please tell me everything that happened while you were waiting to be interviewed. Please start from the moment you entered the waiting room.

2. Now, I'd like you to focus upon telling me what the other people looked like. Attempt to describe them in enough detail so I could recognize them, but remember, $\underline{\text { do not guess }}$ any information. What did the others look like?

3. OK, still focusing upon the other people's appearance, can you describe for me in as much detail as possible what the other people were wearing?

4. Great. Now, I'm interested in what the other people said to each other. Try and remember, in as much detail as possible, what they said to each other whilst you waited. Even fragments of their conversation can be valuable so don't leave out any detail, even it appears irrelevant.'

5. So, I need you describe for me where the others were sat in the waiting room. Please describe where the others were sat relative to where you were sitting.

I'm now going to ask you questions about the surveillance device in the video

6. Please tell me, in as much detail as possible, what the device in the video looked like.

7. Now I need you to recall for me everything you can remember that the device could do. Try and remember, in as much detail as possible, what they said its functions where.

8. Finally, I need you to tell me where the device is going to be planted; please give me as much information about this location as you can recall. 
Running Head: Inoculating truth-tellers' memory as a function of encoding quality

APPENDIX 3. Veracity instructions

Intentional encoding truth-tellers

You are in the 'Blue' team and you will be interviewed by a member of your team so it is important that you are totally truthful to the interviewer and provide as much information as you can recall.

Note that there are also participants on the Red team about today and you should be mindful as to what other teams' members may be doing. If you encounter anyone that uses the words 'Rocket Science' this means that those people are also on your 'Blue' team, if you do not hear those words then they are members of the opposing team and you need to watch out for anything they do as that may be useful to your Blue team.

It is important to appear cooperative. If the interviewer believes you are cooperative you earn $£ 10 / 15$. In addition, you will be entered into a draw to win up to $£ 150$ in prize money. If you do not appear cooperative, you will be asked to write a time-consuming statement about what happened today.

\section{Incidental encoding truth-tellers}

You are in the 'Blue' team and you will be interviewed by a member of your team so it is important that you are totally truthful to the interviewer and provide as much information as you can recall.

It is important to appear cooperative. If the interviewer believes you are cooperative you earn $£ 10 / 15$. In addition, you will be entered into a draw to win up to $£ 150$ in prize money. If you do not appear cooperative, you will be asked to write a time-consuming statement about what happened today.

\section{Intentional encoding liars}

You are in the 'red' team but you will be interviewed by a member of the opposing blue team and as such it is important that you mislead the interviewer about certain details of the video, 
Running Head: Inoculating truth-tellers' memory as a function of encoding quality

including what the device looked like and could do and also the location that is chosen to plant the device. The interviewer knows that the device would be placed somewhere, but does not know where. So, above all, you must not reveal the location that was selected to hide the spy device and your objective is to mislead the investigator by using the third location mentioned in the video as the location that was selected to plant the device.

You also need to mislead the interviewer about the device. The interviewer knows something about the device but does not have all the details, and it is not clear what the interviewer knows. Because of this, you need to provide some truthful and some false information about the device. This will help you to appear cooperative without having to tell the interviewer everything.

In addition, you should be mindful as to what other Red team members may be doing. If you encounter anyone that uses the word 'thermodynamics' this means that those people are also on the Red team. In all likelihood, the interviewer is aware that they are around, so no point to deny that if you see them. However, you should protect them by not telling the truth about what they looked like and what they said.

It is important to appear cooperative. If the interviewer believes you are cooperative you earn $£ 10 / 15$. In addition, you will be entered into a draw to win up to $£ 150$ in prize money. If you do not appear cooperative, you will be asked to write a time-consuming statement about what happened today. 
Running Head: Inoculating truth-tellers' memory as a function of encoding quality

\section{Supplementary analysis}

\section{Exploratory analysis: difference in total detail reported between interviews}

To explore the effect of veracity on the difference in total detail reported between interviews, we conducted an analysis using just the data from the initial interview-present condition. Specifically, we examined the difference in total detail reported between the initial and delayed interviews, for the social interaction only. Difference scores were calculated for each participant by subtracting the total number of details reported in the delayed interview from the total number of details reported in the initial interview.

A one-way Bayesian AVOVA was conducted to explore the effect of Veracity on the difference score. This analysis revealed no significant effect, $F(2,74)=0.037, \mathrm{MSE}=$ $111.000, p=.964, f=0.03, \mathrm{BF}_{01}=8.503$.

\section{Detail reported in the intelligence video}

Note: as the video recording element was included in the design to distract the truthtellers in the incidental encoding condition (incidental truth-tellers) from the real purpose of the experiment (the social interaction), all truth-tellers applied deliberate attention to the video. As such, we expected no differences to emerge between intentional and incidental truth-tellers in detail reported regarding the video.

To examine differences in number of total details reported regarding the intelligence video, we conducted a 3 (Veracity) $\times 2$ (Initial interviewing) ANOVA using total detail reported in the delayed interview as the dependent variable. This analysis revealed a significant main effect for Initial interviewing, $F(1,144)=7.960$, MSE $=3341.760, p=.005$, $f=0.24$. The main effect for Veracity was not significant, $F(2,144)=1.299, \mathrm{MSE}=545.127$, $p=.276, f=0.13, \mathrm{BF}_{01}=31.454$. Furthermore, the Veracity $\mathrm{x}$ Initial interviewing interaction was not significant, $F(2,144)=2.972, \mathrm{MSE}=1247.540, p=.054, f=0.14, \mathrm{BF}_{01}=5.258$. 
Running Head: Inoculating truth-tellers' memory as a function of encoding quality

The Veracity $\mathrm{x}$ Initial interviewing interaction statistics $(p=.054)$ refers to any type of interaction. However, in Hypothesis 1 (regarding the social interaction) we predicted a specific type of interaction: that initial interviewing will have an inoculating effect on truthtellers verbal statements after delays, but not liars. Therefore, a more informative test of Hypothesis 1 in the context of the video recording is to statistically test for significant differences between the initial interview-present and absent conditions, for liars and truthtellers (intentionally encoding and incidentally encoding) separately. This approach, introduced by Nahari and Ben-Shakhar (2011), has now been adapted by others (Nahari, 2017).

Regarding the Veracity $\mathrm{x}$ Initial interviewing interaction, intentional truth-tellers reported significantly more total details in the initial interview-present condition $(M=53.44$, $S D=28.10,95 \% \mathrm{CI}[42.35,65.61])$, than in the initial interview-absent condition $(M=$ $35.24, S D=21.48,95 \%$ CI $[28.14,43.48]), t(48)=2.573, p=.013, d=.73 .95 \% \mathrm{CI}[.14$, 1.29], $\mathrm{BF}_{10}=3.890$. Furthermore, incidental truth-tellers reported significantly more total details in the initial interview-present condition $(M=47.88, S D=16.56,95 \%$ CI [41.04, 54.85]) than in the initial interview-absent condition $(M=36.32, S D=16.10,95 \% \mathrm{CI}[30.12$, $43.17]), t(48)=2.503, p=.016, d=.71 .95 \% \mathrm{CI}[.13,1.27], \mathrm{BF}_{10}=3.400$. However, intentional liars in the initial interview-present conditions $(M=47.88, S D=18.90,95 \% \mathrm{CI}$ $[40.65,54.96])$ and initial interview-absent conditions $(M=49.32, S D=19.43,95 \% \mathrm{CI}$ $[42.00,57.53])$ reported similar amounts of total detail, $t(48)=.266, p=.792, d=.08 .95 \%$ CI $[-.48, .63], \mathrm{BF}_{01}=3.436$. 
Running Head: Inoculating truth-tellers' memory as a function of encoding quality

\section{Declaration of author contribution}

- The study was designed by the first, second and third authors, with comments from the fifth and sixth authors.

- Analysis was performed by the first author, with comments from the second and fifth authors.

- The manuscript was written by the first author, with comments from the second and fifth authors.

- Data was collected by the first and fourth author.

${ }^{\mathrm{I}}$ A favourable ethical review decision was given by the Science Faculty Ethics Committee (SFEC). Our Institution's SFEC conforms to the British equivalent of APA ethical standards (see British Psychological Society, 2009; 2014; 2018). All participants rights were upheld during the research. 